\title{
Comparação de dois testes de neutralização, utilizados no diagnóstico sorológico do vesiculovírus Piry*
}

\section{Comparison of two neutralization test for the use in the Piry serologic vesiculovirus diagnose}

\author{
José Tavares-Neto", Miyoco Abe Owa***, Amélia Travassos da Rosa***, Pedro Vasconcelos****, Luiz T.M. \\ Figueiredo***
}

\begin{abstract}
TAVARES-NETO, J. et al. Comparação de dois testes de neutralização, utilizados no diagnóstico sorológico do vesiculovírus Piry. Rev. Saúde Pública, 27: 373-7, 1993. Realizou-se inquérito sorológico para pesquisar anticorpos neutralizantes contra o vesiculovírus Piry, na cidade de Catolândia-Bahia-Brasil. Duas técnicas de vírus-neutralização foram comparadas em cultura das células $C 6 / 36$, com revelação pelo método imunoenzimático ( TN-C6/36) e em camundongos recém-nascidos (TN-camundongos), que é considerada a prova maior. Em 204 soros, dos 1.274 colhidos, a concordância das duas técnicas foi de $98,7 \%$ $(\mathrm{K}=0,9853)$. Com este resultado do $\mathrm{TN}-\mathrm{C} 6 / 36$, que também é mais exequível, decidiu-se desenvolver o estudo soro-epidemiológico do vesiculovírus Piry, em Catolândia, baseado nesta nova técnica.
\end{abstract}

Descritores: Rhabdoviridae, imunologia. Testes de neutralização, utilização. Sorodiagnóstico, métodos.

\section{Introduçáo}

Entre os ARN vírus da família Rhabdoviridae, gênero Vesiculovirus, encontra-se o Piry, que só foi isolado no território brasileiro ${ }^{19}$, em marsupial ${ }^{4}$ e no homem devido à transmissão acidental em laboratório ${ }^{4,5,624}$. As vesiculoviroses preenchem vários critérios comuns às arboviroses ${ }^{19}$, apesar do sorotipo Piry não ter sido isolado de artrópodos*****19. No caso do Piry, a história natural da infecção não foi esclarecida e não se conhece muitos aspectos epidemiológicos, até pelo número limitado de estudos. Os casos clínicos descritos com o Piry ${ }^{5,6,24}$ tiveram síndrome febril, com início

* Trabalho realizado na Unidade de Pesquisa em Virologia do Departamento de Clínica Médica da Faculdade de Medicina de Ribeirão Preto da Universidade de SãoPaulo e no Instituto Evandro Chagas da Fundação Nacional de Saúde-Belém, PA, subvencionadopeloCNPqe FAPESP. Baseado na Tese de Doutorado de Tavares-Neto, J., 1992, intitulada "Estudo soro-epidemiológico do vesiculovírus Piry na população e entre os membros das familias nucleares, em Catolândia-Bahia", Ribeirão Preto.

** Faculdade de Medicina da Universidade Federal da Bahia e Hospital Couto Maia da Secretaria Estadual de Saúde Salvador, BA - Brasil

*** Faculdade de Medicina de Ribeirão Preto da Universidade de São Paulo - Ribeirão Preto, SP - Brasil

**** Instituto Evandro Chagas da Fundação Nacional de Saúde - Belém, PA - Brasil

Separatas/Reprints: J. Tavares-Neto-RuaMarquês de Caravelas, 262 Ap. 101 - 40140-240 - Salvador, BA Brasil

Edição subvencionada pela FAPESP. Processo Medicina 93/0208-5 abrupto e duração curta, de dois a quatro dias. Na fase de convalescença, a astenia e as mialgias permaneceram por alguns dias ${ }^{5,6}$.

Os vesiculovírus são classicamente diferenciados através dos anticorpos fixadores do complemento e neutralizantes ${ }^{7,19} \mathrm{e}$, mais recentemente, pelosanticorpos monoclonais ${ }^{35}$. A glicoproteína (proteína $\mathrm{G}$ ), do envelope viral, é o antígeno principal, tipo específico, que induz à formação dos anticorpos fixadores do complemento e neutralizantes ${ }^{20}$. Precocemente na infecção aguda, e de forma marcante na fase de convalescença, aparecem os anticorpos neutralizantes, os quais permanecem por longos períodos ou por toda a vida?

No Brasil, a freqüência dos indivíduos com anticorpos neutralizantes anti-Piry varia de 0 a $40,2 \% 8,11,25,31,32$. Em indivíduos adultos de CatolândiaBahia, em estudo sorológico preliminar, a frequiência dos anticorpos neutralizantes anti-Piry foi de $33,3 \%{ }^{33}$, detectados pelo teste de neutralização em camundongos (TN-camundongos). Entretanto, apesar de ser o teste-padrão, a realização deste método requer grande número de camundongos recém-nascidos, o que limita sua aplicação em estudos soroepidemiológicos.

De modo geral os vesiculovírus não replicam tão intensamente nas células de vertebrados como nas de mosquitos $^{13,14,17,34}$. O vírus Piry, como ocorre com vários arbovírus, apresentou replicação evidente em células do clone $\mathrm{C} 6 / 36$ do Aedes albopictus ${ }^{12}$. Porem, as infecções pelo Piry não produzem efeito citopático

****** Comunicação pessoal de N. Dega'llier, no Instituto Evandro Chagas, Belém, PA, em 1991. 
característico. Em vista disto, foi desenvolvida técnica de vírus-neutralização nas culturas de células $\mathrm{C6} / 36$ utilizando, em substituição ao efeito citopático, o método imunoenzimático na revelação.

\section{Material e Método}

\section{Soros Utilizados no Estudo}

Os 204 soros estudados são provenientes de habitantes do Município de Catolândia-Bahia, que participaram de estudo soro-epidemiológicoem $1990^{33}$. Nesse inquérito sorológico colheram-se 1.274 amostras de soros e os resultados serão analisados em outra publicação.

\section{Procedimentos Laboratoriais}

Os procedimentos foram efetuados na Unidade de Pesquisa em Virologia da Faculdade de Medicina de Ribeirão Preto da Universidade de São Paulo. Os testes de neutralização com camundongos foram feitos no Laboratório de Arbovírus do Instituto Evandro Chagas (I E C), da Fundação Nacional de Saúde, Belém-Pará, conforme a seguir descrito.

Culturas Celulares de Aedes albopictus (C6/36) As células C6/36 (originárias da "Arbovírus Research Unit, Yale University, USA)" eram cultivadas em condições estéreis, no meio de Leibowitz L15 ("GIBCO New York, USA"), contendo $10 \%$ de soro fetal bovino inativado pelo calor, $10 \%$ de caldo de triptose fosfato, $100 \mathrm{U} / \mathrm{ml}$ de penicilina e $0,1 \mathrm{ug} / \mathrm{ml}$ de estreptomicina ${ }^{22}$. As colônias das células C6/36 contidas em frascos plásticos estéreis de $25 \mathrm{~cm}^{2}$ (Descarplast ${ }^{R}$ ), em $10 \mathrm{ml}$ do meio de cultivo, foram mantidas a $28^{\circ} \mathrm{C}$ em estufa comum. Os frascos eram observados diariamente em microscópio invertido, até a formação de monocamadas confluentes, quando então as células C6/36 eram utilizadas nos experimentos.

Semente Viral - foi fornecida pelo (IE C) amostra do Piry (estirpe BeAn 24232), oriunda do tecido nervoso de camundongos infectados. O vírus foi primeiramente inoculado em camundongos recém-nascidos (Mus musculus-variedade albino suiço), pela via intracerebral. A maioria dos camundongos desenvolvia encefalite entre 24 e 48 h pós-inoculação, sendo colhidos moribundos e armazenados a $-70^{\circ} \mathrm{C}$.

Numa segunda passagem, o vírus Piry contido em extrato de cérebros de camundongos, diluído a $1 / 10 \mathrm{em}$ PBS ("phosphate-buffered-saline"), pH 7,2 ( $\mathrm{NaCl} 8 \mathrm{~g}$; $\mathrm{KCl} 0,2 \mathrm{~g} ; \mathrm{KH}_{2} \mathrm{PO} 40,2 \mathrm{~g} ; \mathrm{Na}_{2} \mathrm{HPO}_{4}, 12 \mathrm{H}_{2} \mathrm{O} 2.9 \mathrm{~g} ; \mathrm{e} \mathrm{H}_{2} \mathrm{O}$ deionizada $1.000 \mathrm{ml}$ ), foi inoculadonum volume de 500 ul em frascos plásticos de $25 \mathrm{~cm}^{2}$, contendo monocamada confluente de células $\mathrm{C} 6 / 36$. As colônias celulares, após 3 dias e com infecção confirmada por teste de imunofluorescência indireta ${ }^{10}$, eram raspadas e tiveram as células rompidas no próprio meio de cultivo por congelamento e descongelamento. Os debris celulares foram removidos por centrifugação $(2.000 \mathrm{~g}$ por 10 min) e os sobrenadantes foram divididos em alíquotas nos frascos rotulados, com volume de 0,5 a $1 \mathrm{ml} \mathrm{e}$ mantidos congelados a $-70^{\circ} \mathrm{C}$ até o uso. As sementes virais assim preparadas foram utilizadas em todos os experimentos com culturas celulares. Nos testes em camundongos preferiu-se extratos dos cérebros desses animais.

Produção de Fluido Ascítico Imune (FAI) - OFAI foi obtido em camundongos adultos jovens $(M$. musculus). Lotes com dez animais receberam 4 inoculações, uma por semana, contendo $0,1 \mathrm{ml}$ da suspensão do macerado de cérebro de camundongos recém-nascidos infectados com o Piry, diluído $1 / 30 \mathrm{em}$ PBS, com adjuvante completo de Freund ${ }^{18}$, pela via intraperitonial ${ }^{29}$. Cinco dias após a última imunização, todos os animais eram inoculados pela via intraperitonial com células do sarcoma $180 /$ TG e desenvolviam ascite volumosa após uma semana ${ }^{29,30}$. O fluido ascítico imune, rico em anticorpos específicos, foi colhido por punção abdominal, utilizando seringa e aguIha, com retirada de 3 a $5 \mathrm{ml}$ por animal. Após centrifugação o FAI era fracionado em alíquotas em frascos rotulados, com volumes de $1 \mathrm{ml}$ e armazenado a $-20^{\circ}$ até o uso.

Teste de neutralização em células $66 / 36 \mathrm{com}$ leitura imunoenzimática - $\mathrm{O}$ teste de neutralização desenvolvido, utilizando células C6/36 (TN-C6/36), era do tipo vírus-constante ${ }^{30}$.

Numa primeira etapa do teste de neutralização, a semente viral de Piry foi analisada visando à determinação do título; para isto, sofreu diluições decimais em BPS estéril. Microplacas de 96 orifícios contendo células C6/36 foram infectadas com $50 \mathrm{ul} /$ orifício, em sextuplicata para cada diluição viral, incubadas e processadas por método imunoenzimático.

Para o teste de neutralização, previamente, os soros humanos e FAI eram diluídos a 1/10 em PBS estéril e incubados a $56^{\circ} \mathrm{C}$ por $30 \mathrm{~min}$, visando a inativar o complemento outros componentes séricos com ação neutralizante inespecifica ${ }^{15}$.

A semente viral, com título previamente conhecido, era diluída de forma a conter $100 \mathrm{TCID}_{50}$ por $25 \mathrm{ul}$. Os soros humanos, diluídos de $1 / 20$ a $1 / 640$, e o FAI no volume de 25 ul eram misturados a 25 ul da solução viral. Simultaneamente, a titulação do vírus era realizada visando a detectar variações no título conhecido. As titulações virais feitas durante os testes, mostraram variações entre $90-300 \mathrm{TCID}_{50}$. As misturas soro-vírus e a titulação viral eram incubadas por uma hora, a $37^{\circ} \mathrm{C}$ em banho-maria, visando à ligação dos eventuais anticorpos séricos ao vírus e assim a ocorrência de neutralização. Posteriormente estas misturas sorovírus e titulaçðes eram inoculadas em duplicata, no volume de 50 ul, em orifícios de microplacas contendo 
células $\mathrm{C} 6 / 36$. As microplacas eram incubadas a $28^{\circ} \mathrm{C}$ por $48 \mathrm{~h}$, tempo adequado para a replicação viral ${ }^{12}$. Para a interrupção da replicação viral e fixação das células, adicionava-se solução de formalina tamponada (50 ul/ orifício) aos orifícios. As microplacas, com a solução de formalina tamponada, eram incubadas por uma noite a $4^{\circ} \mathrm{C}$ e em seguida os orifícios eram lavados três vezes em PBS e secos, quando eram então processadas (reveladas) pelo teste imunoenzimático.

Método imunoenzimático de leitura do TN-C6/36 Em cada orifício, das microplacas, foram acrescentados 100 ul do FAI de Piry, na diluição 1/100 em PBS. Após a incubação a $37^{\circ} \mathrm{C}$ por uma hora, os orifícios eram lavados por três vezes com PBS, sendo posteriormente secos. Numa segunda etapa se adicionava aos orifícios $100 \mathrm{ul}$ do anticorpo de cabra anti-IgG de camundongo conjugado à peroxidase (SIGMA, USA), diluído $1 / 2.000 \mathrm{em}$ PBS. Seguia incubação a $37^{\circ} \mathrm{C}$ por uma hora, lavagem dos orifícios por cinco vezes em PBS e secagem. A finalização do teste se fazia com a adição de 200 ul do substrato OPD (o-phenylenediamine dihydrocloride/SIGMA,USA), preparado pela mistura de $10 \mathrm{mg}$ de $\mathrm{OPD}$, em $6 \mathrm{ml}$ da solução de ácido cítrico $0,1 \mathrm{M}$, à qual também se adicionava $6,5 \mathrm{ml}$ da solução de fosfato dibásico $0,2 \mathrm{M}$ e $12,5 \mathrm{ml}$ de água destilada contendo 40 ul de peróxido de hidrogênio. As placas eram novamente incubadas por aproximadamente 20 min a $37^{\circ} \mathrm{C}$, seguindo a leitura qualitativa dos testes, de forma visual ${ }^{1,28}$ observando-se a cor amarela nos orifícios em que ocorria infecção viral e comparando-a à dos orifícios da coluna 12 da mesma microplaca (controles negativos). $O$ título neutralizante, anti-Piry de um soro, era dada pela maior diluição do mesmo, que inibia a replicação viral determinada pela ausência de cor no teste imunoenzimático, os títulos recíprocos maiores ou iguais a 20 foram considerados positivos.

\section{Teste de Neutralização em Camundongos}

(TN-camundongos) - O teste de neutralização com vírus-diluído e soro-constante, em camundongos recém-nascidos (TN-camundongos), foi efetuado para o vírus Piry, segundo metodologia descrita ${ }^{23,30}$. Corresponde ao teste clássico e "golden standard" (provamaior) para o diagnóstico sorológico de infecções por vesiculovírus, usando soros controles positivos e negativos. A semente-vírus Piry (BeAn 24232), no TNcamundongos, era proveniente de cérebros de camundongos recém-nascidos com título de $10^{5,8} \mathrm{LD}_{50} / \mathrm{ml}$, em média, com variação de $10^{5,7}$ a $10^{4,9} \mathrm{LD}_{50} / \mathrm{ml}$.

$O$ resultado deste teste é dado pelo índice logarítmico de neutralização (ILN), que é a diferença entre os valores logarítmicos dos títulos $\mathrm{LD}_{50}{ }^{23,26}$ obtidos nas titulações do vírus puro e vírus mais soro em teste. Valores de $\mathbb{L N}$ soro $>1,7$ são considerados positivos.

Análise Estatística - Na análise comparativa das duas técnicas de neutralização, o índice Kappa (K) foi utilizado na avaliação da concordância sorológica, de acordo com Kramer \& Feinstein ${ }^{21}$ que tem significância estatística quando o índice $\mathrm{K}>0,60(\mathrm{p}<0,01)$.

\section{Resultados}

Cento e setenta e três soros com anticorpos neutralizantes anti-Piry pelo TN-C6/36 e 31 Piry-negativos tiveram os resultados comparados pelo TN-camundongo. A distribuição dos $\mathbb{L} \mathrm{N}\left(\mathrm{n}=\mathrm{n}^{2}\right.$ de soros) observada foi: $K 1,7(34) ; 1,8 \vdash|2,6(19) ; 2,7 \longmapsto| 3,5$ (37) e 3,6 $|-|>/ 4,4$ (114).

Entre os negativos, o $\mathbb{L N}$ teve limites de $k 0,6 \mathrm{a} k$ 1,2; entre os Piry-positivos os limites foram de 2,1 a>/4,4.

$\mathrm{Na}$ Tabela 1 esses resultados foram associados aos observadosno TN-C6/36. A co-positividade $(100,0 \%)$, a co-negatividade $(91,2 \%)$ e a concordância $(98,5 \%)$ foram elevadas; a discordância (falsos-positivos e negativos) dos resultados foi baixa $(1,5 \%)$.

Tabela 1. Comparação dos resultados observados no teste de neutralização contra o Piry, em camundongos recémnascidos $(R N)$ e em células $C 6 / 36$.

\begin{tabular}{cccc}
\hline Teste neutralização & \multicolumn{3}{c}{ RN } \\
\cline { 2 - 3 } & + & - & Total \\
\cline { 2 - 4 } & $+170^{\mathrm{a}}$ & $3^{\mathrm{b}}$ & 173 \\
$\mathrm{C} 6 / 36$ & $0^{\mathrm{c}}$ & $31^{\mathrm{d}}$ & 31 \\
\hline Total & 170 & 34 & $204^{\mathrm{n}}$ \\
\hline
\end{tabular}

co-positividade $(a / a+c): 100,0 \%$ co-negatividade $(d / b+d): 91,2 \%$ concordância $(a+d / n): 98,5 \%$ discordância $(b+c / n): 1,5 \%$ índice Kappa (K): 0,9853; sendo,

$$
\begin{aligned}
& P_{0}=0,9850 \\
& P_{\theta}=0,7320 \\
& s(K)=0,0432 \\
& z=22,81 \\
& P<0,0000001
\end{aligned}
$$

Mesmo considerando a prova-maior, o TN-camundongo (RN), os exames sorológicos com os três soros discordantes foram repetidos (Tabela 2).

Os mesmos resultados foram confirmados, em ambos os testes, evidenciando, desta forma, a reprodutibilidade das duas técnicas.

As proporções anteriores (co-positividade e conegatividade) referidas na Tabela 1 não expressam, acuradamente, o grau de agregação entre os dois métodos utilizados (TN-C6/36 e TN-camundongos). $\cdot$ Ao contrário do índice "Kappa" (K), através da distribui- 
ção normal (z), baseado na proporção da concordância observada e a esperada, respectivamente, $P_{o}=98,5 \%$ e $P_{e}=73,2 \%$; sendo $K=0,9853$. Os valores de $K$ entre 0,81 e 1,0 são considerados "quase perfeitos", segundo Kramer \& Feinstein ${ }^{21}$. O desvio-padrão (s) de K foi de 0,0432 e $z=22,81$, mostrando a agregação altamente significante $(\mathbf{p}<0,0000001)$ dos dois métodos.

Tabela 2. Exames sorológicos com 3 tipos de soros discordantes.

\begin{tabular}{|c|c|c|c|c|}
\hline \multirow[b]{3}{*}{ NN Soro } & \multicolumn{4}{|c|}{ TN } \\
\hline & \multicolumn{2}{|c|}{18} & \multicolumn{2}{|c|}{$2^{9}$} \\
\hline & $\begin{array}{c}\text { RN } \\
\text { (ILN) }\end{array}$ & C6/36 & $\begin{array}{c}\text { RN } \\
(\text { ILN) }\end{array}$ & $C 6 / 36$ \\
\hline $\begin{array}{l}1.335 \\
1.834 \\
2.079\end{array}$ & $\begin{array}{l}k<1,1 \\
k<0,9 \\
k 1,4\end{array}$ & $\begin{array}{l}+ \\
+ \\
+\end{array}$ & $\begin{array}{l}k 1,4 \\
k 0,9 \\
k 0,9\end{array}$ & $\begin{array}{l}+ \\
+ \\
+\end{array}$ \\
\hline
\end{tabular}

\section{Discussáo e Conclusóes}

As células $\mathrm{C} 6 / 36$ foram permissivas à infecção pelo vesiculovírus Piry. Anteriormente, a replicação dos vesiculovírus $\mathrm{Cocal}^{2}$, Alagoas ${ }^{3}$, Indiana- ${ }^{16}$, New Jersey $^{13}$ e Piry ${ }^{12}$ já havia sido observada nas células $\mathrm{C} 6 / 36$. Os efeitos citopáticos não foram notados, tanto nas culturas de $\mathrm{C} 6 / 36$ com o vírus estudado, como nas observações anteriores ${ }^{12,13,34}$.

As células $\mathrm{C} 6 / 36$ foram resistentes aos contaminantes ambientais (bactérias e fungos), usando antibióticos no meio de cultura. Mesmo quando as condiçס̃es de trabalho no fluxo laminar não eram adequadas, -falta de energia elétrica ou durante o preparo dos soros - as quais eram em grande número no teste de neutralização em $\mathrm{C} 6 / 36$ (TN-C6/36), sendo realizadas as diluições fora da cabine do fluxo laminar. Porém, não ocorreu contaminação até o $5^{\circ}$ dia após a diluição. Este dado facilitou o trabalho com as células $\mathrm{C} 6 / 36$ e poderá ser útil nos serviços sem recursos materiais sofisticados ou nos trabalhos de campo.

Os 204 soros ensaiados por ambos os testes de neutralização (nas células $\mathrm{C} 6 / 36$ e em camundongos recém-nascidos) tiveram $98,5 \%$ dos resultados concordantes. Com esses resultados optou-se pela utilização do teste de neutralização nas células C6/36(TN-C6/36), no levantamento sorológico ${ }^{33}$. Caso a opção fosse 0 teste de neutralização em camundongos e considerando o uso de três diluições para cada soro a ser testado, na totalidade do inquérito $(n=1.274)$, e seis camundongos recém-nascidos por diluição, seriam necessários 22.932 animais para a análise com o vesiculovírus Piry. Nesse cálculo, foram excluídos os animais testados com as titulações do vírus e do soro-homólogo.

Deste modo, o teste de neutralização nas células
C6/36 (TN-C6/36) mostrou-se extremamente útil para a pesquisa dos anticorpos neutralizantes contra os vesiculovírus. Em estudos soro-epidemiológicos, para estes vírus, os anticorpos neutralizantes devem ser pesquisados por serem os únicos que persistem por longo tempo ${ }^{10,28}$; principalmente em medicina veterinária, desde quando a estomatite pelo vesiculovírus é o principal diagnóstico diferencial da febre aftosa.

Não encontramos na literatura estudo comparativo entre o teste de neutralização em camundongos (prova-maior)e o TN-C6/36napesquisa dos anticorpos neutralizantes anti-vesiculovírus, especialmente contra o Piry. Além disto, o TN-C6/36 teve reprodutibilidade adequada os 173 soros Piry-positivos e os 31 Pirynegativos tiveram os resultados iguais, em duas ocasiões diferentes, sendocada uma em duplicata. Inclusive, os três soros discordantes, com resultados negativos, detectados pelo TN-camundongos, tiveram os mesmos resultados positivos no TN-C6/36 quando o teste foi repetido.

Contudo, a reprodutibilidade deveria ser medida pelo valor da absorbância fornecida pela leitura espectrofotométrica ${ }^{28}$ que não foi utilizada por falta de condiçð̃es materiais e porque se buscava montar técnica não dependente de equipamentos sofisticados. No futuro, seriaaconselhável compararosníveis daabsorbância do TN-C6/36 com os ILN encontrados no TN-camundongos.

Através da leitura visual, pela intensidade da cor, do TN-C6/36, não foi possível associar aos valores dos ILN para o Piry. Mas a taxa de concordância observada evidencia a aplicabilidade e a praticidade da leitura visual, mostrando ao mesmo tempo que a coloração nos casos Piry-negativos e a ausência de cor dos Pirypositivos tem diferença facilmente detectável e discriminante.

Portanto, o teste de neutralização nas células C6/ 36 é aplicável em levantamentos sorológicos, também por requerer biotério com estrutura menor e a análise de vários soros ao mesmo tempo, facilitando, assim, os trabalhos de campo, inclusive na área da medicina veterinária.

TA VARES-NETO, J. et al. [Comparison of two neutralization test for the use in the Piry serologic vesiculovirus diagnose]. Rev. Saúde Pública, 27:373-7, 1993. A serological survey of Piry was undertaken of the sera of inhabitants of Catolância - Bahia State, Brazil. Serum results obtained by a vesiculovirus neutralization test of $C 6 / 36$ cells read by ELISA are compared with those obtained by the classic technique, carried out on newborn mice. The agreement between the results was as high as $98.7 \%$ of the 204 sera tested and the neutralization test of C6/36 cells was chosen as the most suitable technique for the serosurvey testing.

Keywords: Rhabdoviridae, imunology. Neutralization tests, utilization. Serodiagnosis, methods. 


\section{Referências bibliográficas}

1. ARBELÁEZ, G. Febre aftosa em búfalos indianos (Bubalus bubalis, Linnaeus 1758) em bovinos conviventes no Estado de São Paulo: avaliação do estado imunitárioe dos portadores do vírus. São Paulo,1990. [Tese de Doutorado-Instituto de Ciências Biomédicas da USP].

2. ARTSOB, H. \& SPENCE, L. Growth of vesicular stomatitis virus in mosquito cell lines. Can. J. Microbiol., 20: 32936,1974 .

3. BARRY, C. et al. Comparative susceptibility of four mosquito cell lines to Alagoas arbovirus. An. Microbiol., 23: 51-7, 1978.

4. Belem Virus Laboratory. Annual Report, 1960. p.52.

5. Belem Virus Laboratory. Annual Report, 1964. p.38 - 40.

6. Belem Virus Laboratory. Annual Report, 1969. p. 7 - 8.

7. CALISHER, C.H. et al. Antigenic relationships among Rhabdoviruses from vertebrates and hematophagous arthropods. Intervirology, 30: 241-57, 1989.

8. CASTRO, M.G. et al. On-going study on arbovirosis in Rio de Janeiro State. In: Virológica 91. Belém, Sociedade Brasileira de Virologia, 1991. p. 4.

9. FENNER, F. et al. Veterinary virology. Orlando, Academic Press Inc., 1987.

10. FERNÁNDEZ, P.J. Application of monoclonal antibodies in indirect immunofluorescence for diagnostic subtyping of vesicular stomatitis (Indiana serotype). New Haven, 1988. [Master of Public Health - Yale University].

11. FIGUEIREDO, L.T.M. Estudo sobre infecções por arbovírus na região de Ribeirão Preto, Estado de São Paulo. Ribeirão Preto, 1985. [Tese de Doutoramento - Faculdade de Medicina de Ribeirão Preto da USP].

12. FIGUEIREDO, L.T.M. Uso de células de Aedes albopictus C6/36 na propagação e classificação e arbovírus das famílias Togaviridae, Flaviviridae, Bunyaviridae e Rhabdoviridae. Rev.Soc Bras.Med.Trop., 23: 13-8, 1990.

13. FRANCY,D.B.et al. Epizö̈tic vesicular stomatitis in Colorado, 1982 isolation of virus from insects collected along the northern Colorado rocky moutain Front Range. J.Med Entomol.,25:343-7,1988.

14. GILLIES, S. \& STOLLAR, V. The production of high yields of infectious vesicular stomatitis virus in Aedes albopictus cells and comparisons with replication in BHK-21 cells. Virology, 107:509-13,1980.

15. GOBET, R. et al. The role of antibodies in natural and acquired resistance of mice to vesicular stomatitis virus. Exp. Cell Biol., 56: 175-80, 1988.

16. HAY, R. et al.Catalogue of cell linesand hydridomas. Rockville, American Type Culture Collection, 1985.

17. HENCHAL, E.A. et al. Rapid identification of dengue virus isolates by using monoclonal antibodies in an indirect immunofluorescence assay. Am. J. Trop. Med. Hyg., 32: 164-9, 1983.

18. HERBERT, W.J. Mineral-oil adjuvants and the immunization of laboratory animals, In: Weir, D.M. Handbook of experimental immunology. Oxford, Blackwell Scientific Publications, 1973, p.A2-1-A2-14.

19. KARABATSOS, N. International catalogue of arboviruses: including certain other viruses of vertebrates. 3 th ed. San Antonio, American Society of Tropical Medicine and Hygiene, 1985.
20. KELLEY, J.M. The glycoprotein of vesicular stomatitis virus is the antigen that gives rise to and reacts with neutralizing antibody. J. Virol., 10:1231-5, 1972.

21. KRAMER, M.S. \& FEINSTEIN, A.R. Clinical biostatistics: the biostatistics of concordance. Clin. Pharmacol. Therap., 29:111-23, 1981.

22. LEIBOVITZ, A. The growth and maintenance of tissue-cell cultures in free gas exchange with the atmosphere. Am.J. Hyg., 78:173-80,1963.

23. LENNETTE, E. Laboratory viral. In: Lennette, E. \& Schmidt, N.J. Diagnostic procedures for viral, rickttsial and chlamydialinfections. Washington, American Public Health Association, 1969. p. 46-52.

24. PINHEIRO,F.P. Piry fever, In: Beran, G.W.ed. Viral zoonoses. Boca Raton, Florida, CRC press, 1981. p. 187-90. (CRC Handbook Series in Zoonoses, Section B).

25. PINHEIRO, F.P. et al. Vigilancia e investigación de las enfermedades infecciosas a lo largo de la carretera tranzamazonicadelBrasil. Bol.Ofic. Sanit.Panam., 77:18798, 1974.

26. REED, L.J. \& MUENCH, H. A simple method of estimating fifty percent endpoinsts. Am.J. Hyg., 27:493-7, 1938.

27. RODRIGUEZ, L.L. et al. Sewrologicalmonitoring of vesicula stomatitis New Jersey virus in enzootic regions of Costa Rica. Am. J. Trop. Med. Hyg., 42: 272-81, 1990.

28. ROMANO, N.S. O uso do teste imunoenzimáticona vigilância epidemiológica de arboviroses. São Paulo, 1990. [Dissertação de mestrado -Faculdade de Saúde Pública da USP].

29.SARTORELLI, A.C. et al. Use of sarcoma 180/TG to prepare hyperimmune ascitic fluid in the mouse. J. Immunol., 96: 676-82, 1966.

30. SHOPE, R.E. \& SATHER, G.E. Arborivuses. In: Lennette E. \& Schmidt, N.J. Diagnostic procedures for viral, rickettsial and chlamydial infections. Washington, American Public Health Association, 1979. p. 767-814.

31. TAVARES-NETO, L. et al. Pesquisa de anticorpos para arbovírus no soro de residentes no povoado de Corte de Pedra, Valença, Bahia. Mem. Inst. Oswaldo Cruz, 81: 3518, 1986.

32. TAVARES-NETO, J. et al. Freqüência de anticorpos neutralizantes contra o vesiculovírus Piry, em doadores de sangue de Uberaba, Minas Gerais, Brasil. Rev. Inst. Med. Trop. S.Paulo, 32:211-4, 1990.

33. TAVARES-NETO, J. Estudo soro-epidemiológico do vesiculovírus Piry na população e entre os membros das famílias nucleares, em Catolândia - Bahia, Ribeirão Preto, 1992. [Tese de Doutorado- Faculdade de Medicina de Ribeirão Preto da USP].

34. TESH, R.B. A method for the isolation and identification of dengue viruses, using mosquito cells cultures. Am.J.Trop Med.Hyg., 28: 1053-9, 1979.

35. WAGNER, R.R. Rhabdoviridae and their replication. In: Fields, B.N. \& KNIPE, D.M. Virology, New York, Raven Press, 1990. p. 867-81.
Recebido para publicação em 5.5 .93 Aprovado para publicação em 20.8 .93 